совершенствованию лекционной формы обучения в вузе могут внедрение активных и интерактивных методов обучения и применение электронных средств обучения [3].

$$
* * *
$$

1. Ощепкова О.В. Лекция как активная форма вузовского обучения // СНВ. - 2013. - №4 (5). - С. 123125.

2. Гакаев Р.А. Лекция как ведущий компонент системы вузовского образования // Педагогика высшей школы. - 2015. - № 3 (3). - С. 62-64.

3. Гайнутдинов Р.Г. Развитие лекции как формы организации обучения в высшей школе в условиях информатизации образования // КПЖ. - 2014. - №2 (103). - С. 102-103.

\title{
Гулякин Д.В. \\ Педагогический подход к формированию социально-информационной культуры студентов технического вуза
}

Кубанский государственный технологический университет (Россия, Краснодар)

doi: 10.18411/lj-04-2021-144

\section{Аннотация}

В статье рассмотрен педагогический подход процесса формирования социальноинформационной культуры студентов, как составляющей профессиональной культуры.

Ключевые слова: культура, личность, профессиональная культура, социальноинформационная культура.

\section{Abstract}

The article considers the pedagogical approach of the process of forming the social and informational culture of students as a component of professional culture.

Key words: culture, personality, professional culture, social and informational culture.

Педагогический подход предполагает создание таких сред образования, которые бы взаимообогащали обучающегося человека и культуру в целом, и таких пространств, которые позволяли студенту раскрыть личностные смыслы профессиональной культуры в частности. Следовательно, в значительной степени актуализируется проблема реорганизации образовательного процесса в вузе, в направлении личностного становления специалиста.

С позиций педагогического подхода формирование личности есть ее целенаправленное воспитание (А.С. Макаренко назвал этот процесс «проектированием личности»). С точки зрения этого подхода необходимо выяснить, что и как должно быть сформировано в личности, чтобы она отвечала социально обусловленным требованиям, которые предъявляет к ней общество (вычленение задач и способов формирования личности).

Педагоги Матрос Д.Ш., Полев Д.М., Мельникова Н.Н. рассматривают процесс формирования личности как освоение им внутреннего, индивидуальнопсихологического и внешнего, общечеловеческого (культурного богатства) потенциала возможностей.

К.К. Платонов заостряет внимание на прогрессивной тенденции в изменении личности, ее содержательном обогащении в результате целенаправленных воздействий на нее. Специфическое для личности формирование - это целенаправленное обогащение ее содержательной стороны путем превращения отражаемой реальности, лежащей вне этих рамок, в отраженное, входящее в ее рамки, т.е. беспрерывное присвоение мира личностью. Данная позиция сближает формирование с процессом воспитания и по механизму, и по результатам, так как в общепризнанном понимании воспитание рассматривается как процесс 
целенаправленного влияния, целью которого выступает накопление индивидом необходимого для жизни в обществе социального опыта и формирования у него принимаемой обществом системы ценностей.

Формирование человека как личности традиционно выступает целью системы образования. Исследователи в области философии педагогики (Н.В.Кузьмина, Е.В. Бондаревская, Д.Ш. Матрос, и др.) критикуют сегодня его классическую парадигму, направленную на подготовку человека как личности, готовой к жизни и труду. Такое образование, как отмечают исследователи, рассматривает человека как простую систему, как объект педагогического воздействия.

Отличительной чертой современного образования, в том числе и высшего, является рассмотрение его сущности, целей и смысла через призму представлений о человеке. Современная профессиональная педагогика ориентирует образование на необходимость создания условий, преодолевающих разрыв человека и культуры, условий, раскрывающих человеку личностный смысл культуры и образования как культурного обогащения. Актуальной становится задача формирования в образовательном процессе высшей школы будущего специалиста как личности.

Исследования проблемы формирования личности, взаимодействия культуры и личности, культуры и творчества, развития индивидуального стиля профессиональной деятельности широко отражены в работах ученых Е.М.Бабосова, Б.С.Библера, Л.Н.Когана, А.Н.Леонтьева, С.В. и др.

Культура личности формируется как совокупность определенных знаний, умений, навыков, ценностных ориентаций, образа мышления, способов действий в различных ситуациях, творчества, деятельности, общения и т.д. Уровень культуры определяется через соответствующие поступки человека как по отношению к окружающему миру, так и по отношению к себе.

Профессиональная культура является одним из уровней общей культуры человека. Профессиональная культура - это конструируемая система знаний, умений и навыков специалиста. Процесс формирования профессиональной культуры специалиста находится в зависимости от ряда факторов, к которым можно отнести «объективные и субъективные, более и менее значимые, личностные и социальные. Объективное воздействие оказывают общемировые тенденции в образовании, социально-философские проблемы культуры, состояние системы образования и качество образовательных услуг, культура образовательного учреждения, престижность профессии в обществе. Среди субъективных факторов - общая культура и мотивация личности, получающей профессиональное образование[1].

Тенденции развития современного социума выдвигают требования к современному специалисту, к его социально-информационным профессионально-значимым качествам, как целенаправленное воздействие на процесс формирования социально-информационной культуры будущих специалистов.

Процесс формирования социально-информационной культуры будущего специалиста на протяжении всех этапов обучения является отражением социокультурных изменений, происходящих в формирующемся информационном обществе.

Современная педагогика говорит о реализации процесса формирования культуры личности в виде целостной педагогической системы.

С педагогической точки зрения понятие «система» довольно подробно рассмотрено в работах СИ. Архангельского, Ю.К. Бабанского, В.П. Беспалько, Л.Г. Викторовой, Т.А. Ильиной, Н.В. Кузьминой, В.В. Игнатова, В.Г. Афанасьева, А.М. Моисеева, В.А. Сластенина, Ю.П. Сокольникова, Л.Ф. Спирина, П.И. Третьякова, Л.С. Подымова, М.М. Поташника, И.М. Титовой, Т.И. Шамовой, Э.Г. Юдина, И.Я. Лернер, М.Н. Скаткин и др.

По мнению С.И. Архангельского, система - это «множество взаимосвязанных компонентов, составляющих определенное целое в своем строении и функционировании»[2] . 
В понимании В.П. Беспалько, система - это «любой процесс, протекающий в определенных условиях, в совокупности с этими условиями»[3].

В.В. Игнатова, под педагогической системой понимает совокупность факторов, условий и средств организации того или иного процесса и их реализации посредством специальных педагогических форм, методов и приемов (технологий) с учетом критериев эффективности их реализации.

Процесс формирования «некоего личностного качества» специалиста в условиях профессиональной подготовки с методологической точки зрения необходимо рассмотреть с позиций целостного подхода. Логика и последовательность реализации целостного подхода к процессу формирования «некоего личностного качества» рассматривается Н.К. Сергеевым. Ученый выделяет шесть узловых этапов применения целостного подхода к педагогическим исследованиям (педагогической системе):

- формулировка представлений о сущности, функциях, составе, структуре формируемого феномена;

- осуществление сквозь «призму» данных представлений ретроспективного анализа проблемы, оценка ее состояния и современной теории и педагогической практики;

- разработка научных представлений о сущности, функциях, составе и структуре, уровнях становления и развития исследуемого качества как целостного феномена в структуре целостности более высокого порядка;

- формулировка представлений о возможностях различных педагогических средств, которые наряду с представлениями о логике становления и развития качества необходимы для более целенаправленного конструирования эффективного целостного процесса;

- обоснование и реализация модели целостного процесса формирования изучаемого качества, которая должна соответствовать объективной логике становления и развития качества, носить этапный характер, отражающий постепенность, непрерывность и преемственность становления свойств личности, носить целостный характер в аспекте «статической и динамической структур процесса»;

- на всех этапах и во всех ситуациях целостного процесса должно реализовываться стремление педагога органично включать «свой» процесс в реально осуществляемый целостный педагогический процесс.

Высказанные положения являются ориентиром разработки педагогической системы формирования социально-информационной культуры, как одного из компонентов профессиональной культуры будущих специалистов.

Таким образом, под процессом формирования социально-информационной культуры студентов, как составляющей профессиональной культуры, мы понимаем, направленное воздействие педагогической системы на личностно-профессиональное становление будущих инженеров, позволяющее адаптироваться в социальноинформационной деятельности в качестве навыка вхождения в информационное общество[4].

$$
* * *
$$

1. Гулякин Д.В. Информационная культура и ее аспекты // В сборнике: ВУЗОВСКАЯ НАУКА СЕВЕРО-КАВКАЗСКОМУ РЕГИОНУ. МатериалЫ ХІІІ научно-технической конференции. Главный редактор: Синельников Б.М., 2009. С. 181.

2. Архангельский С. И. // Больш. совет. энцикл.: в 30 т. / Гл. ред. А.М. Прохоров. - М.: Сов. энцикл., 1970. - Т. 2: Ангола-Барзас. - Стб. 822-823.

3. Беспалько В. П. Образование и обучение с участием компьютеров. - Москва: МПСИ, 2002. -352 с.

4. Gulyakin D, Babaeva E., Magomedova R., Panova I. и др. Transgression of culturological approach in the practise of the Russian higher education. // Life Sci J 2014;11(9s):188-191, USA, (ISSN:1097-8135). http://www.lifesciencesite.com. 36 . 